\title{
Skin bruising, adrenal function and markers of bone metabolism in asthmatics using inhaled beclomethasone and fluticasone
}

\author{
J.-L. Malo*, A. Cartier*, H. Ghezzo*, S. Mark**, J. Brown ${ }^{+}$, M. Laviolette ${ }^{\ddagger}$ L.-P. Boulet
}

Skin bruising, adrenal function and markers of bone metabolism in asthmatics using inhaled beclomethasone and fluticasone. J.-L. Malo, A. Cartier, H. Ghezzo, S. Mark, J. Brown, M. Laviolette, L.-P. Boulet. C) ERS Journals Ltd 1999.

ABSTRACT: Fluticasone propionate (FP) is generally considered to have twice the efficacy of beclomethasone dipropionate (BDP) on a weight-to-weight basis for the control of asthma, and may have lesser effects on adrenal function. However, the effects of FP and BDP on skin integrity and bone metabolism markers require further examination.

Sixty-nine asthmatic subjects were enrolled in a double-blind crossover study in which, after a baseline period, they received BDP or FP (at half the dose of BDP) for two 4-month periods each. A questionnaire on skin bruising, a skin examination, tests of adrenal function and of markers of bone metabolism were performed after 2 months of each period.

The number of asthma exacerbations was not significantly different for the two treatment periods (eight for BDP and nine for FP), nor were various indices of asthma control. Whereas the frequency of bruising reported by the questionnaire was not different, there were more bruises on examination for BDP $(1.6 \pm 2.5)$ than for $\mathrm{FP}(1.2 \pm 2.3)(p=0.04)$. Although baseline serum cortisol was not significantly different for the two drugs, the increase in cortisol after cortrosyn was lower for BDP (357 \pm 158 $\left.\mu \mathrm{mol} \cdot \mathrm{dL}^{-1}\right)$ than for FP $\left(422 \pm 144 \mu \mathrm{mol} \cdot \mathrm{dL}^{-1}\right)(\mathrm{p}<0.01)$. Serum osteocalcin levels were significantly lower in subject on BDP $\left(2.8 \pm 1.7 \mu \mathrm{g} \cdot \mathrm{mL}^{-1}\right)$ than on FP $\left(3.5 \pm 1.9 \mathrm{ng} \cdot \mathrm{mL}^{-1}\right)$ $(p=0.003)$. Other markers of bone metabolism were not significantly altered. The three major side-effects were loosely, but significantly correlated with the periods on BDP and FP. However, skin bruises, increase in cortisol after Cortrosyn and osteocalcin were not significantly correlated for the period on either BDP or FP.

In conclusion, whereas fluticasone propionate used at half the dose of beclomethasone dipropionate has a comparable effect on the control of asthma, fluticasone propionate demonstrated fewer side-effects in terms of skin bruising, adrenal suppression and bone metabolism.

Eur Respir J 1999; 13: 993-998

The use of inhaled corticosteroids (ICS) has represented a major breakthrough in the treatment of asthma since their introduction in the 1970s. Beclomethasone dipropionate (BDP) was the first ICS to be used. Multiple studies carried out in approximately 20,000 subjects and summarized elsewhere have demonstrated that these preparations lack systemic side-effects provided that the dose is kept low [1]. In the case of inhaled BDP in adults, this threshold dose is close to $1 \mathrm{mg} \cdot$ day $^{-1}$

In recent years, high doses of ICS have been advocated for the treatment of asthma. Doses of BDP from 1-2 $\mathrm{mg} \cdot \mathrm{day}^{-1}$, and of budesonide from $0.8-1.6 \mathrm{mg} \cdot \mathrm{day}^{-1}$, are now frequently prescribed to treat moderate-to-severe asthma. Systemic absorption is considered to be low with these doses, but some blockade of the hypothalamo-pituitary-adrenocortical (HPA) axis has been described [2]. This blockade does not appear to have clinical implications [3]. However, recent concerns have been raised about the possibility of glaucoma [4] and cataracts [5] with the use of high doses of ICS. Lower values of serum
*Dept of Chest Medicine, Hôpital du Sacré-Coeur, Montréal, Québec, Canada. **Glaxo Wellcome Canada Inc., Mississauga, Ontario, Canada. ${ }^{+}$Centre hospitalier de l'Université Laval, Sainte-Foy, Québec, Canada. ${ }^{\star}$ Centre de pneumologie, Hôpital Laval, Sainte-Foy, Québec, Canada.

Correspondence: J.-L. Malo

Dept of Chest Medicine

Hôpital du Sacré-Coeur

5400 West Gouin Blvd

Montréal

Canada H4J $1 \mathrm{C} 5$

Fax: 15143383123

\section{Keywords: Adrenal}

asthma

bone metabolism

glucocorticosteroids

skin bruising

Received: July 291998

Accepted after revision December 271998

Partially supported by the Centre d'excellence en santé respiratoire, FRSQ-Bureau d'affaires du Québec, and Glaxo Wellcome Canada Inc. osteocalcin and higher urinary phosphorus have been found in subjects using high doses of inhaled BDP or budesonide, but effects on bone density remain uncertain [6]. Corticosteroids may have other side-effects primarily affecting the skin, such as acne [7], skin thinning and bruising, which have all been associated with ICS $[8,9]$. A prior study determined that 71 of 100 subjects on inhaled BDP $\left(\geq 1 \mathrm{mg} \cdot \mathrm{day}^{-1}\right)$ and budesonide $\left(\geq 0.8 \mathrm{mg} \cdot \mathrm{day}^{-1}\right)$ reported skin bruising compared with $32 \%$ of a control group paired for age and sex, and that this side-effect was more pronounced in older females and associated with lower urinary and blood cortisol levels [10].

Fluticasone propionate (FP) is a new, topically active, synthetic androstane carbothioate glucocorticosteroid, with negligible oral bioavailability [11]. FP has been shown to be more powerful than BDP on a weight-to-weight basis in controlling asthma symptoms and functional indices of airway calibre [12-15]. There are discrepancies among the results of doses of FP and BDP, with FP administered at half the dose of BDP on the HPA axis [13-15]. 
However, in these studies the frequency of cutaneous side-effects was not assessed, nor were parameters of bone metabolism evaluated.

It was therefore decided to initiate a double-blind, crossover, prospective study in asthmatic subjects requiring 800-2,000 $\mu \mathrm{g} \cdot \mathrm{day}^{-1}$ BDP or budesonide to explore the potential for cutaneous side-effects, bone metabolism markers and effects on the HPA axis of BDP and FP, ensuring that the control of asthma was not different with the two treatments. Subjects were asked to take either the same dose of BDP or half the daily dose of FP for two 4-month periods in a double-blind, crossover manner. The hypothesis was that FP would result in fewer cutaneous and bone metabolism side-effects and less effect on adrenal function.

\section{Subjects and methods}

\section{Subjects}

Sixty-nine adult ( $>18$ yrs old) asthmatic subjects who fulfilled the criteria for asthma as defined by the American Thoracic Society [16] were included. Out of approximately 200 subjects taking ICS at a dose equivalent to 1 $\mathrm{mg} \cdot$ day $^{-1}$ of BDP, almost 100 satisfied the entry criteria and 69 agreed to participate. All participants demonstrated a $>15 \%$ improvement in forced expiratory volume in one second (FEV1) either spontaneously or after treatment in the 2 yrs preceding their entry into the study. Asthma had to be moderate-to-severe, but had to have been stable for at least 3 months prior to the study. Subjects should not have taken oral steroids on a continuous basis for $>1 \mathrm{yr}$ in the previous $5 \mathrm{yrs}$. They could be included if they had only required short courses of oral steroids, but not if they had taken more than three courses per year, and not if they had taken any in the 3 months preceding the study. Patients who reported bleeding disorders, or took aspirin or nonsteroidal anti-inflammatory drugs or anticoagulants were excluded. Patients were excluded if they were current smokers or if they had used tobacco products within the preceding year.

\section{Study design}

Patients continued to take their usual ICS therapy during the run-in period of 2 weeks. On entry into the study treatment period, patients discontinued their usual inhaled ICS therapy and took only the ICS provided in the study treatment packs. The stability of asthma was assessed during the run-in period. At the end of the 2 weeks, skin bruising, spirometry before and $15 \mathrm{~min}$ after inhaled salbutamol $(200 \mu \mathrm{g})$ given by a metered dose inhaler (MDI), cortisol pre-Cortrosyn and post-Cortrosyn injection, and bone metabolism markers were assessed. Subjects were then sequentially randomized to receive either the same dose of BDP they had been on (if they had been on budesonide, the nearest higher BDP dose on a weight-toweight basis was used (viz $0.8 \mathrm{mg}$ budesonide corresponded to $1 \mathrm{mg}$ BDP, $1.2 \mathrm{mg}$ budesonide to $1.5 \mathrm{mg}$ BDP and $1.6 \mathrm{mg}$ budesonide to $2 \mathrm{mg} \mathrm{BDP}$ ), or half the daily dose of FP. Subjects were reassessed 8 weeks later at the same time of the day (i.e. morning or afternoon) by questionnaire, skin examination and spirometry, and at 16 weeks after the initial assessment by questionnaire, skin examination, cortisol pre-Cortrosyn and post-Cortrosyn, urinary cortisol, spirometry pre- and post-200 $\mu \mathrm{g}$ salbutamol, and bone metabolism markers. Subjects were then given the alternate treatment and reassessed 8 and 16 weeks later at the same time of the day and with the same parameters as for the first treatment period. Of the 67 subjects who entered the two periods of treatment, 33 were initially randomized to BDP and 34 initially to FP. BDP and FP inhalers were provided in the MDI form and the inhalation technique was verified at each visit.

Oral steroids were given in the event of an asthmatic exacerbation as indicated by the use of $>8$ puffs of rescue salbutamol in a $24 \mathrm{~h}$ period, effectiveness of rescue salbutamol lasting $<3 \mathrm{~h}$, wakening due to asthma symptoms, or loss of a day at work because of asthma symptoms. In the event of sustained improvement after 10 days of oral steroid treatment, subjects continued in the study by being given the alternate treatment regimen. In the event of two asthmatic exacerbations in the same treatment period or absence of improvement on oral steroids, subjects were withdrawn from the study.

\section{Parameters studied}

A diary on daily asthma symptoms and rescue salbutamol use was completed by each patient for the 2 weeks preceding their visit. The number and distribution of purpuric skin lesions were assessed by skin examination [10]. The frequency of skin bruising (on a scale of 1-4: 1 , none; 2 , occasionally, i.e. once or twice per month; 3 , commonly, i.e. once or twice per week; 4 , often, i.e. daily) and severity (1, spontaneously; 2 , after rubbing; 3 , on a blow; 4, after removing a plaster) were assessed by questionnaire [10]. Blood levels of cortisol before and $30 \mathrm{~min}$ after Cortrosyn (25 U) were assessed.

Twenty-four-hour urine samples were collected to test for cortisol, phosphorus, calcium and N-telopeptides. Serum intact osteocalcin was measured with a human immunoradiometric assay using two monoclonal antibodies recognizing the 5-13 and 43-49 amino acid sequences of the molecule and purified intact human bone osteocalcin as a standard. The intra-assay and interassay coefficients of variation $(\mathrm{CV})$ were $<5 \%$, and the sensitivity was 0.3 $\mathrm{ng} \cdot \mathrm{mL}^{-1}[17]$. Urinary N-telopeptides were measured with an enzyme-linked immunosorbent assay (ELISA) (Osteomark, Ostex International, Seattle, WA, USA) using a monoclonal antibody directed against the N-telopeptide to helix intermolecular crosslinking domain of type I collagen isolated from human urine. The sensitivity of the assay was $25 \mathrm{nmol} \cdot \mathrm{L}^{-1}$. Serum procollagen and specific alkaline phosphatase were assessed using commercial immunoassay kits (Metra BioSystems Inc., Mountain View, CA, USA).

\section{Analysis of results}

Chi-squared analysis, paired t-tests, regression analysis and analysis of variance (ANOVA) were used where appropriate. All data were normally distributed as verified by a Kolmogorov-Smirnov one-sample test, which allowed parametric tests to be carried out, except for urinary phosphorus for which a nonparametric test (KolmogorovSmirnov two-sample test) was used. 
Table 1. - Subjects' baseline anthropometric, clinical and respiratory functional results

\begin{tabular}{lc}
\hline Sex M/F & $30 / 39$ \\
Age yrs & $48.4 \pm 14.5$ \\
Acute reversibility to inhaled salbutamol ${ }^{\#}$ & $13.4 \pm 10.4$ \\
$\quad(\% \Delta$ FEV1) & $51 / 67(76 \%)$ \\
Atopy* & \\
Smoking history n & 31 \\
$\quad$ Exsmokers & 38 \\
$\quad$ Nonsmokers & $21.2 \pm 14.6$ \\
Duration of asthma yrs & $76 \pm 18$ \\
FEV1 (\% pred) & \\
Baseline treatment mg daily dose $\mathrm{n}$ & 17 \\
budesonide 0.8 & 2 \\
budesonide 1.2 & 7 \\
budesonide 1.6 & 29 \\
BDP 1 & 14 \\
BDP 2 & \\
\hline
\end{tabular}

Data are presented as mean \pm SD unless indicated otherwise. *: defined as at least one immediate reaction to a battery of 15 common inhalants; the atopic status was unknown for two subjects. ${ }^{+}: 62 \%(42)$ subjects with a forced expiratory volume in one second (FEV1) $<80 \%$ predicted; ${ }^{\#}$ : on entry into the study. M: male; F: female; BDP: beclomethasone dipropionate.

\section{Results}

The baseline characteristics of the 69 subjects included in the study are shown in table 1 . Sixty-two per cent of the subjects had an FEV $1<80 \%$ predicted. On entry into the study, $27 / 69$ subjects $(39 \%)$ had a $>15 \%$ improvement in FEV1 15 min after inhaled salbutamol. Twenty-six subjects $(38 \%)$ were on budesonide and $43(62 \%)$ were on BDP in the baseline period. Two subjects had unstable asthma as judged by their diary (awakenings at night with asthma symptoms) in the entry period, leaving 67 subjects.

Table 2 gives information on various parameters used to assess the stability of asthma in the treatment periods. These were not significantly different for the BDP and FP periods.
Table 3 presents the data related to the side-effects. Although skin bruising was not significantly different in terms of the number of subjects affected, its severity and frequency, as well as the number of bruises on direct examination were significantly greater in subjects taking BDP (mean 1.64 lesions on BDP and 1.24 lesions on FP). Although 24-h urinary cortisol and baseline plasma cortisol were not significantly different, post-Cortrosyn cortisol values were lower when subjects were on BDP, and the difference between the pre-Cortrosyn and postcortrosyn values was significantly different by a mean of $95 \mu \mathrm{mol} \cdot \mathrm{dL}^{-1}$ in the BDP and the FP periods. In addition, osteocalcin was significantly lower when subjects were on BDP than when they were on FP. Table 4 shows that the increase in cortisol after Cortrosyn and the difference in osteocalcin levels were significantly more pronounced when the order of administration of treatment was BDP followed by FP, whereas the difference in the number of skin bruising events was greater when the order of administration of treatment was FP followed by BDP. There was no significant carry-over or period effects.

There was a satisfactory correlation between the improvement in cortisol after Cortrosyn while on FP and BDP $(\mathrm{r}=0.49, \mathrm{p}<0.001)$. The same applied to osteocalcin levels while on the two drugs $(r=0.54, p<0.001)$. There was also a borderline association between the presence or absence of skin bruising while on each of the two drugs $\left(\chi^{2}=3.6\right.$, $\mathrm{p}=0.06)$. However, there were no significant relationships between each of the three outcomes, i.e. the increase in cortisol after Cortrosyn versus skin bruising, increase in cortisol after Cortrosyn versus osteocalcin levels, and skin bruising versus osteocalcin levels while on each of the two drugs.

\section{Discussion}

Whereas the efficacy, the effect on the HPA axis and the local side-effects (oropharyngeal candidiasis) of ICS have been well examined in the course of clinical trials, their systemic specific organ-directed side-effects have not

Table 2. - Efficacy parameters used to assess the stability of asthma during the different treatment periods

\begin{tabular}{|c|c|c|c|c|c|c|c|c|c|c|}
\hline \multirow[b]{2}{*}{ Parameter } & \multirow[b]{2}{*}{ Baseline } & \multicolumn{3}{|c|}{ FP } & \multicolumn{3}{|c|}{ BDP } & \multicolumn{3}{|c|}{ Comparison p-value } \\
\hline & & 8 weeks & 16 weeks & Total & 8 weeks 1 & 16 weeks & Total & 8 weeks & 16 weeks & Total \\
\hline Number of exacerbations* & NA & 8 & 1 & 9 & 3 & 5 & 8 & 0.1 & 0.5 & 0.4 \\
\hline $\begin{array}{l}\text { Number of subjects with at least one } \\
\text { nocturnal awakening due to asthma }\end{array}$ & $\mathrm{NA}$ & 10 & 5 & 15 & 7 & 3 & 10 & 0.5 & 0.5 & 0.3 \\
\hline $\begin{array}{l}\text { Number of subjects with symptoms } \\
\text { on awakening in the morning }\end{array}$ & $\mathrm{NA}$ & 31 & 26 & 37 & 27 & 20 & 31 & 0.6 & 0.3 & 0.3 \\
\hline \multicolumn{11}{|l|}{$\begin{array}{l}\text { Number of subjects who required } \\
\text { salbutamol during the day }\end{array}$} \\
\hline $6-10$ puffs $\cdot$ period $^{-1}$ & NA & 7 & 5 & 5 & 8 & 9 & 8 & 0.8 & 0.3 & 0.4 \\
\hline $11-20$ puffs $\cdot$ period $^{-1}$ & NA & 7 & 10 & 12 & 11 & 7 & 13 & 0.3 & 0.5 & 0.9 \\
\hline$>20$ puffs $\cdot$ period $^{-1}$ & $\mathrm{NA}$ & 20 & 15 & 26 & 15 & 16 & 23 & 0.3 & 0.9 & 0.3 \\
\hline FEV1 \% pred** & 75.8 & 78.3 & 77.2 & 77.5 & 77.6 & 77.3 & 77.5 & 0.5 & 0.9 & 0.7 \\
\hline & \pm 17.4 & \pm 18.0 & \pm 17.1 & \pm 17.1 & \pm 18.2 & \pm 17.9 & \pm 17.5 & & & \\
\hline FVC $\%$ pred $^{* *}$ & $\begin{array}{c}90.5 \\
\pm 14.6\end{array}$ & $\begin{array}{c}91.6 \\
\pm 13.4\end{array}$ & $\begin{array}{c}90.0 \\
\pm 13.1\end{array}$ & $\begin{array}{c}90.5 \\
\pm 12.8\end{array}$ & $\begin{array}{c}91.1 \\
\pm 14.2\end{array}$ & $\begin{array}{c}90.3 \\
\pm 13.7\end{array}$ & $\begin{array}{c}90.7 \\
\pm 13.0\end{array}$ & 0.9 & 0.9 & 0.7 \\
\hline
\end{tabular}

*: use of $>8$ puffs of rescue salbutamol in a 24-h period, effectiveness of rescue salbutamol lasting $<3 \mathrm{~h}$, wakening due to asthma symptoms, and/or loss of a day at work because of asthma symptoms. **: mean \pm SD. FEV1: forced expiratory volume in one second; FVC: forced vital capacity; BDP: beclomethasone dipropionate; FP: fluticasone propionate; NA: not applicable. In the baseline period, 43 subjects took BDP and 26 budesonide. 
Table 3. - Side-effects for the two inhaled corticosteroid treatments

\begin{tabular}{|c|c|c|c|c|c|c|c|c|c|c|}
\hline & \multirow[b]{2}{*}{ Baseline } & \multicolumn{3}{|c|}{ FP } & \multicolumn{3}{|c|}{ BDP } & \multicolumn{3}{|c|}{ Comparison p-value } \\
\hline & & 8 weeks & 16 weeks & Total & 8 weeks & 16 weeks & Total & 8 weeks & 16 weeks & Total \\
\hline \multicolumn{11}{|l|}{ Skin bruising questionnaire } \\
\hline Subjects $\mathrm{n}$ & 37 & 32 & 33 & 47 & 38 & 32 & 43 & 0.9 & 0.7 & 0.5 \\
\hline Severity* & $\begin{array}{c}2.27 \\
(0.91)\end{array}$ & $\begin{array}{l}1.97 \\
(0.96)\end{array}$ & $\begin{array}{l}1.88 \\
(0.96)\end{array}$ & $\begin{array}{l}1.43 \\
(0.96)\end{array}$ & $\begin{array}{c}1.69 \\
(0.89)\end{array}$ & $\begin{array}{c}1.84 \\
(0.93)\end{array}$ & $\begin{array}{l}1.46 \\
(0.80)\end{array}$ & 0.1 & 0.8 & 0.3 \\
\hline Frequency** & $\begin{array}{c}2.24 \\
(0.87)\end{array}$ & $\begin{array}{l}2.17 \\
(0.96)\end{array}$ & $\begin{array}{c}2.33 \\
(0.83)\end{array}$ & $\begin{array}{l}1.53 \\
(0.98)\end{array}$ & $\begin{array}{l}2.21 \\
(0.90)\end{array}$ & $\begin{array}{l}2.47 \\
(0.63)\end{array}$ & $\begin{array}{l}1.90 \\
(0.88)\end{array}$ & 0.5 & 0.3 & 0.3 \\
\hline Examination & $\begin{array}{l}1.57 \\
(2.4)\end{array}$ & $\begin{array}{l}1.13 \\
(2.3)\end{array}$ & $\begin{array}{l}1.45 \\
(2.9)\end{array}$ & $\begin{array}{l}1.24 \\
(2.3)\end{array}$ & $\begin{array}{l}1.67 * \\
(2.5)\end{array}$ & $\begin{array}{l}1.64 \\
(3.1)\end{array}$ & $\begin{array}{l}1.64 \\
(2.5)\end{array}$ & 0.03 & 0.3 & 0.04 \\
\hline \multicolumn{11}{|l|}{ Cortisol $\mu \mathrm{mol} \cdot \mathrm{dL}^{-1}$} \\
\hline 24-h urinary & $\begin{array}{l}133 \\
(95)\end{array}$ & $\mathrm{NA}$ & $\begin{array}{l}105 \\
(64)\end{array}$ & NA & NA & $\begin{array}{l}109 \\
(80)\end{array}$ & $\mathrm{NA}$ & NA & 0.6 & NA \\
\hline Pre-Cortrosyn & $\begin{array}{c}442 \\
(219)\end{array}$ & $\mathrm{NA}$ & $\begin{array}{c}410 \\
(249)\end{array}$ & NA & NA & $\begin{array}{l}418 \\
(245)\end{array}$ & $\mathrm{NA}$ & $\mathrm{NA}$ & 0.7 & $\mathrm{NA}$ \\
\hline Post-Cortrosyn & $\begin{array}{l}873 \\
(282)\end{array}$ & $\mathrm{NA}$ & $\begin{array}{c}834 \\
(292)\end{array}$ & NA & NA & $\begin{array}{c}774 \\
(270)\end{array}$ & $\mathrm{NA}$ & NA & 0.09 & $\mathrm{NA}$ \\
\hline Cortisol change (post-pre) & $\begin{array}{c}431 \\
(230)\end{array}$ & $\mathrm{NA}$ & $\begin{array}{l}422 \\
(144)\end{array}$ & NA & $\mathrm{NA}$ & $\begin{array}{c}357 \\
(158)\end{array}$ & $\mathrm{NA}$ & $\mathrm{NA}$ & 0.005 & NA \\
\hline Urinary calcium $\mu \mathrm{mol} \cdot \mathrm{L}^{-1}$ & $\begin{array}{l}1.52 \\
(3.3)\end{array}$ & $\mathrm{NA}$ & $\begin{array}{l}1.12 \\
(1.2)\end{array}$ & $\mathrm{NA}$ & NA & $\begin{array}{l}1.11 \\
(1.2)\end{array}$ & $\mathrm{NA}$ & NA & 0.9 & NA \\
\hline Urinary phosphorus $\mu \mathrm{mol} \cdot \mathrm{L}^{-1}$ & $\begin{array}{l}9.4 \\
(10.7)\end{array}$ & $\mathrm{NA}$ & $\begin{array}{c}10.7 \\
(12.4)\end{array}$ & $\mathrm{NA}$ & NA & $\begin{array}{l}10.0 \\
(11.7)\end{array}$ & NA & NA & 0.7 & $\mathrm{NA}$ \\
\hline Serum osteocalcin $\mathrm{ng} \cdot \mathrm{mL}^{-1}$ & $\begin{array}{l}3.3 \\
(1.7)\end{array}$ & NA & $\begin{array}{l}3.5 \\
(1.9)\end{array}$ & NA & $\mathrm{NA}$ & $\begin{array}{l}2.8 \\
(1.7)\end{array}$ & $\mathrm{NA}$ & NA & 0.003 & $\mathrm{NA}$ \\
\hline $\begin{array}{l}\text { Urinary N-telopeptides } \\
\mu \mathrm{M} \text { creatinine }{ }^{-1}\end{array}$ & $\begin{array}{l}43.1 \\
(30.6)\end{array}$ & NA & $\begin{array}{c}34.4 \\
(18.4)\end{array}$ & NA & NA & $\begin{array}{c}33.4 \\
(17.7)\end{array}$ & $\mathrm{NA}$ & NA & 0.9 & $\mathrm{NA}$ \\
\hline $\mathrm{P} 1 \mathrm{CP} \mathrm{ng} \cdot \mathrm{mL}^{-1}$ & $\begin{array}{c}85.4 \\
(35.4)\end{array}$ & $\mathrm{NA}$ & $\begin{array}{l}89.7 \\
(29.5)\end{array}$ & NA & NA & $\begin{array}{c}92.2 \\
(42.8)\end{array}$ & NA & NA & 0.6 & $\mathrm{NA}$ \\
\hline $\begin{array}{l}\text { Bone specific alkaline phosphatase } \\
U \cdot L^{-1}\end{array}$ & $\begin{array}{c}9.4 \\
(10.7)\end{array}$ & $\mathrm{NA}$ & $\begin{array}{l}16.4 \\
(7.3)\end{array}$ & $\mathrm{NA}$ & NA & $\begin{array}{l}15.8 \\
(6.1)\end{array}$ & NA & $\mathrm{NA}$ & 0.4 & $\mathrm{NA}$ \\
\hline
\end{tabular}

Data are presented as mean(SD). *: on a scale from 1-4 (1, spontaneously; 2 , after rubbing; 3 , on a blow; 4 , after removing a plaster); **: from 1-4 (1, none; 2 , occasionally, i.e. once or twice per month; 3, commonly, i.e. once or twice per week; 4, often, i.e. daily) for those who reported skin bruising. NA: not applicable. P1CP: procollagen type 1 carboxyterminal peptide; FP: fluticasone propionate; BDP: beclomethasone dipropionate. In the baseline period, 43 subjects took BDP and 26 budesonide.

generally been reported. In recent years, various organdirected side-effects have been described in subjects on high-dose ICS. These include cutaneous, bone and ocular manifestations as well as reduced growth in children [18]. To the authors' knowledge, this is the first study comparing BDP and FP for their effect on skin, bone metabolism and the HPA axis. It was demonstrated that FP, given at half the BDP dose, provided similar asthma control to BDP but caused less skin bruising, reduced the serum osteocalcin decrease and the depression of the Cortrosyn-induced secretion of cortisol. Consequently, these data suggest an advantage of FP over high doses of BDP in that FP is locally more active than BDP on a weight-for-weight basis and causes fewer systemic side- effects at half the dose of BDP. However, these data were generated by using fixed doses of FP and BDP and without generating a dose-response curve for each treatment. Such a design would have been preferable to ascertain a more precise correspondence between efficient and harmless doses for each drug. The same criticisms can be addressed to previous studies that have examined the efficacy of the two drugs and not their sideeffects on skin, bone metabolism and the HPA axis [12$15]$.

Although the magnitude of the side-effects, i.e. skin bruising, the response of cortisol to Cortrosyn and osteocalcin levels were significantly different for the periods on BDP and FP, they were significantly, though only mildly,

Table 4. - Effect of the order of inhaled corticosteroid administration on selected parameters

\begin{tabular}{|c|c|c|c|c|c|c|c|c|}
\hline & \multicolumn{4}{|c|}{ Initial treatment } & \multicolumn{4}{|c|}{ Second treatment } \\
\hline & Baseline & BDP & FP & p-value* & Baseline & FP & BDP & p-value* \\
\hline $\begin{array}{l}\text { Increase in cortisol } \\
\text { after Cortrosyn } \mu \mathrm{mol} \cdot \mathrm{dL}^{-1}\end{array}$ & $437 \pm 141$ & $338 \pm 146$ & $420 \pm 137$ & 0.02 & $403 \pm 183$ & $424 \pm 153$ & $377 \pm 169$ & 0.25 \\
\hline Ecchymoses $n$ & $3.17 \pm 4.61$ & $2.57 \pm 3.20$ & $2.03 \pm 2.77$ & 0.22 & $3.39 \pm 5.96$ & $3.36 \pm 6.11$ & $4.19 \pm 6.55$ & 0.03 \\
\hline Osteocalcin $\mathrm{ng} \cdot \mathrm{mL}^{-1}$ & $3.48 \pm 1.78$ & $2.88 \pm 1.61$ & $3.79 \pm 2.13$ & 0.05 & $3.10 \pm 1.63$ & $3.22 \pm 1.65$ & $2.75 \pm 1.79$ & 0.22 \\
\hline
\end{tabular}

Data are presented as mean $\pm \mathrm{SD} .{ }^{*}$ : p-value obtained from a two-way analysis of variance (nonparametric analysis for number of ecchymoses; parametric analysis for increase in cortisol after Cortrosyn and osteocalcin); BDP: beclomethasone dipropionate; FP: fluticasone propionate. 
associated or related. This suggests that switching from one ICS to another is less likely to result in the disappearance of the side-effect, although it can be reduced, particularly in the specific switch from BDP to FP. Another interesting finding of this study is that the three side-effects that significantly distinguished between BDP and FP were not correlated or associated. In a prior study, it was demonstrated that the subjects with skin bruising also had the lower urinary cortisol levels [10], suggesting that skin bruising was mediated through systemic absorption. Consequently, if the three side-effects are independent in the same subject, it strengthens the need for monitoring each of these possible side-effects individually.

The present study focused on possible cutaneous and bone effects, the rationale being that skin bruising is a common side-effect in subjects on high-dose ICS [10] and reduced osteocalcin is a sensitive marker for systemic absorbtion of ICS [19]. Not all variables included in the current study were discriminants of the effects of BDP and FP. Direct examination of the skin for bruising was more discriminating than the questionnaire, although a higher prevalence of abnormalities had been found with the questionnaire than with direct examination in a previous study [10]. The explanation for this is hypothetical. Subjects may recall that they have easy skin bruising, but it may be more difficult for them to identify whether this skin bruising is better or worse over limited intervals.

Besides osteocalcin, urinary phosphorus has been shown to be lower in subjects on high-dose ICS [6]. In the present study, urinary phosphorus was not a significant discriminant of the effects of BDP and FP. However, the present results are in keeping with the results of ToOGOOD et al. [19] and WISNIEWSKI et al. [20], who found that high dose ICS reduced osteocalcin levels with minimal effects on other parameters of bone metabolism. In a randomized, crossover study consisting of two 6-week treat-ment periods, Bоотsмa et al. [21] found that FP at a dose of $0.75 \mathrm{mg} \cdot$ day $^{-1}$ had no significant effect on bone me-tabolism, whereas BDP at a dose of $1.5 \mathrm{mg} \cdot \mathrm{day}^{-1}$ decreased both osteocalcin and procollagen type I collagen carboxyterminal telopeptide. PAUwELs et al. [22] recently showed that osteocalcin and bone density were improved in subjects on $0.25 \mathrm{mg} \cdot \mathrm{day}^{-1} \mathrm{FP}$ treatment in comparison with a $0.5 \mathrm{mg} \cdot \mathrm{day}^{-1} \mathrm{BDP}$ treatment. They detected no difference in serum cortisol but did not examine skin effects. In the present study, baseline 24-h urinary cortisol and plasma cortisol were similar for the two treatments, but the response to cortrosyn was different. The latter test is generally considered more sensitive in detecting an abnormality in adrenal function [18].

The advantages or disadvantages of ICS should be thoroughly evaluated not only for their possible effects on the HPA axis but also for possible organ-specific sideeffects. The present study focused on some of these, but others could be explored. Indeed, the possibility of glaucoma in specific groups of subjects (elderly patients on high doses of ICS) [4] and cataracts [5] has also been recently raised.

In summary, this study found that fluticasone propionate administration resulted in fewer side-effects than beclomethasone diproprionate in terms of skin bruising, osteocalcin levels and the hypothalamo-pituitary-adrenocortical axis function in asthmatic subjects requiring high doses of inhaled corticosteroids. The clinical control of asthma was no different. For such subjects, fluticasone propionate, which has a better innocuity profile, should be preferred to bectomethasone dipropionate.

\author{
Acknowledgements. The authors thank L. \\ Schubert for reviewing this manuscript.
}

\section{References}

1. Huskisson SC, Meades CR, Cuss FM, Palmer JBD. Inhaled Beclomethasone Dipropionate. Castle Press Abertwyth, Glaxo Group Research Ltd., Greenford, England 1987.

2. Smith MJ, Hodson ME. Effects of long term inhaled high dose beclomethasone dipropionate on adrenal function. Thorax 1983; 38: 676-681.

3. Toogood JH. Complications of topical steroid therapy for asthma. Am Rev Respir Dis 1990; 141: S89-S96.

4. Garbe E, LeLorier J, Boivin JF, Suissa S. Inhaled and nasal glucocorticoids and the risks of ocular hypertension or open-angle glaucoma. JAMA 1997; 277: 722-727.

5. Cumming RG, Mitchell P, Leeder SR. Use of inhaled corticosteroids and the risk of cataracts. $N$ Engl J Med 1997; 337: 8-14.

6. Boulet LP, Giguère MC, Milot J, Brown J. Effects of long-term use of high-dose inhaled steroids on bone density and calcium metabolism. J Allergy Clin Immunol 1994; 194: 796-803.

7. Monk B, Cunliffe WJ, Layton AM, Rhodes DJ. Acne induced by inhaled corticosteroids. Clin Exp Dermatol 1993; 18: 148-150.

8. Capewell S, Reynolds S, Shuttleworth D, Edwards C, Finlay AY. Purpura and dermal thinning associated with high dose inhaled corticosteroids. BMJ 1990; 300: 15481551 .

9. Mak VHF, Melchor R, Spiro SG. Easy bruising as a sideeffect of inhaled corticosteroids. Eur Respir J 1992; 5: 1068-1074.

10. Roy A, Leblanc C, Paquette L, et al. Skin bruising in asthmatic subjects treated with high doses of inhaled steroids: frequency and association with adrenal function. Eur Respir J 1996; 9: 226-231.

11. Fuller R, Johnson M, Bye A. Fluticasone propionate - an update on preclinical and clinical experience. Respir Med 1995; 89: SA3-SA18.

12. Fabbri L, Burge PS, Croonenborgh L, et al. Comparison of fluticasone propionate with beclomethasone dipropionate in moderate to severe asthma treated for one year. Thorax 1993; 48: 817-823.

13. Barnes NC, Marone G, Di Maria GU, et al. A comparison of fluticasone propionate, $1 \mathrm{mg}$ daily, with beclomethasone dipropionate, $2 \mathrm{mg}$ daily, in the treatment of severe asthma. Eur Respir J 1993; 6: 877-884.

14. Leblanc P, Mink S, Keistinen T, Saarelainen PA, Ringdal N, Payne SL. A comparison of fluticasone propionate 200 $\mu \mathrm{g} /$ day with beclomethasone dipropionate $400 \mu \mathrm{g} /$ day in adult asthma. Allergy 1994; 49: 380-385.

15. Lundback B, Alexander M, Days J, et al. Evaluation of fluticasone propionate $\left(500 \mu \mathrm{g} \cdot \mathrm{day}^{-1}\right)$ administered either as dry powder via Diskhaler inhaler or pressurized inhaler and compared with beclomethasone dipropionate (1000 $\mu \mathrm{g} \cdot \mathrm{day}^{-1}$ ) administered by pressurized inhaler. Respir Med 1993; 87: 609-620.

16. American Thoracic Society. Standards for the diagnosis and care of patients with chronic obstructive pulmonary 
disease (COPD) and asthma. Am Rev Respir Dis 1987; 136: 225-244.

17. Garnero P, Grimaux M, Séguin P, Delmas PD. Characterization of immunoreactive forms of human osteocalcin generated in vivo and in vitro. J Bone Miner Res 1994; 9: 255-264.

18. Lipworth BJ, Secki JR. Measures for detecting systemic bioactivity with inhaled and intranasal corticosteroids. Thorax 1997; 52: 476-482.

19. Toogood JH, Jennings B, Hodsman AB, Baskerville J, Fraher LJ. Effects of dose and dosing schedule of inhaled budesonide on bone turnover. J Allergy Clin Immunol 1991; 188: 572-580.

20. Wisniewski AF, Lewis SA, Des Green J, Maslanka W,
Burrell H, Tattersfield AE. Cross sectional investigation of the effects of inhaled corticosteroids on bone density and bone metabolism in patients with asthma. Thorax 1997; 52: 853-860.

21. Bootsma GP, Dekhuijzen PNR, Festen J, Mulder PGH, Swinkels LMJW, van Herwaarden CLA. Fluticasone propionate does not influence bone metabolism in contrast to beclomethasone dipropionate. Am J Respir Crit Care Med 1996; 153: 924-930.

22. Pauwels RA, Yernault JC, Demedts MG, Geusens P, on behalf of the Belgian multicenter study group. Safety and efficacy of fluticasone and beclomethasone in moderate to severe asthma. Am J Respir Crit Care Med 1998; 157: $827-832$. 